\title{
Representação social da criança sobre o câncer*
}

\author{
CHILDREN'S SOCIAL REPRESENTATION OF CANCER \\ REPRESENTACIÓN SOCIAL DE LOS NIÑOS A RESPECTO DEL CÂNCER
}

\author{
Elaise Regina Gonçalves Cagnin ${ }^{1}$, Noeli Marchioro Liston ${ }^{2}$, Giselle Dupas ${ }^{3}$
}

\begin{abstract}
RESUMO
Esta pesquisa foi inspirada na necessidade de aprofundar conhecimentos acerca da assistência à criança com câncer. $O$ objetivo do trabalho foi de desvendar as representações sociais da criança com câncer. Realizamos 10 entrevistas do tipo aberta, com crianças e adolescentes de 9 a 15 anos. Os núcleos de análise emergentes giraram em torno da doença, do tratamento, dos profissionais da área da saúde e relações familiares.

Este trabalho traz as representações sociais pertencentes ao núcleo doença, objetivando a melhor compreensão sobre o tema e possibilitando o direcionamento da assistência de enfermagem com vistas a diminuição dos traumas que este processo desencadeia na criança.
\end{abstract}

\author{
PALAVRAS-CHAVE \\ Neoplasias. \\ Criança. \\ Percepção social.
}

\author{
ABSTRACT \\ This research was motivated \\ by the need to know more \\ about the care of children \\ with cancer. The objective \\ of the study was to discover \\ what the social representation \\ of the child with cancer are. \\ Ten open interviews were \\ conducted with children and \\ teenagers from 9 to 15 years \\ of age. The analysis issues \\ that emerged from the \\ children's discourse were \\ about the disease, the \\ treatment, the health care \\ workers and family \\ relationships. The present \\ study presents the social \\ representation of the disease, \\ with the objective of better \\ understanding the topic and \\ directing nursing care \\ towards a minimization \\ of the trauma which \\ this process brings upon \\ the children.
}

\section{KEYWORDS}

Neoplasms.

Child.

Social perception.

\section{RESUMEN}

Esta investigación se inspiró en la necesidad de profundizar en los conocimientos referentes a la asistencia de niños con cáncer. La propuesta es descubrir las representaciones sociales de los niños con cáncer. Fueron realizadas 10 entrevistas de tipo abierta, a niños y adolescentes de 9 a 15 años. Los núcleos de análisis han sido enfermedad, tratamiento, profesionales responsables del área de la salud y relaciones familiares. Este trabajo incluye las representaciones sociales que pertenecen al núcleo enfermedad, con la finalidad de mejorar la comprensión sobre el asunto y hacer posible el direccionamiento de la asistencia de enfermería con las perspectivas de reducción de traumas que el proceso puede desencadenar en los niños.

\section{PALABRAS CLAVE}

Neoplasmas.

Niño.

Percepcion social.
* Parte do trabalho de Iniciação Científica $\mathrm{PIBIC/CNPq/UFSCar} \mathrm{-}$ 2001

1 Aluna do curso de Enfermagem da Universidade Federal de São Carlos (UFSCar)

2 Enfermeira, Professor Adjunto do Departamento de Enfermagem da UFSCar. noeli@power.ufscar.br

3 Enfermeira, Professor Adjunto do Departamento de Enfermagem da UFSCar. gdupas@power.ufscar.br 
Elaise Regina G Cagnin Noeli Marchioro L Ferreira Giselle Dupas

\section{INTRODUÇÃO}

Câncer é o nome dado a um conjunto de mais de 250 doenças que apresentam causas, manifestações, tratamento e prognósticos diferentes e que têm em comum o crescimento desordenado de células que invadem os tecidos e órgãos, podendo espalhar-se para outras regiões do corpo ${ }^{(1)}$.

À medida que as células cancerosas vão substituindo as normais, os tecidos invadidos vão perdendo suas funções, uma vez que essas células, geralmente, são menos especializadas nas suas funções do que as suas correspondentes normais ${ }^{(2)}$.

Podem originar-se em todo e qualquer tecido humano e em qualquer idade ${ }^{(3)}$. A oncogênese é resultante da mutagênese de células normais, determinada por agente cancerígeno ou fatores etiológicos que podem ser agrupados em físicos, químicos e biológicos ${ }^{(4)}$.

A incidência das neoplasias malignas em crianças não é tão alta como em adultos, porém no Brasil apresenta-se como a terceira causa de morte na população abaixo de 14 anos, excluindo-se os acidentes e as causas externas ${ }^{(5)}$. A incidência e a mortalidade de algumas neoplasias pediátricas variam bastante conforme a idade, o tempo para o diagnóstico, permanecendo as causas ainda como desconhecidas, mas na maioria das enfermidades são invocados dois grupos de fatores básicos: relacionados ao ambiente $\mathrm{e}$ ao indivíduo ${ }^{(6)}$.

Segundo os estudos, tem-se verificado um aumento progressivo, e também linear, das taxas de incidência dos tumores da criança, sobretudo a Leucemia Linfóide Aguda (LLA), os tumores do sistema nervoso central (SNC), os linfomas não-Hodgkin, o tumor de Wilms e outros tumores renais. Como exemplo temos que: no Brasil, de dez a quinze casos de câncer, entre indivíduos com menos de 15 anos de idade, quatro são de LLA. Paralelamente, desde 1970, vem-se observado um aumento linear das taxas de cura dos tumores na infância, estando estas atualmente nos Estados Unidos, variando entre $70 \%$ e $90 \%$ dos casos. No Brasil, as crianças e jovens com LLA curam-se em $70 \%$ e $80 \%$ dos casos ${ }^{(5)}$.

Por estes estudos pode-se verificar que está havendo mudanças no perfil epidemiológico dessa moléstia pois, há cerca de duas décadas, o câncer infantil era considerado uma doença aguda e de evolução invariavelmente fatal, sendo uma das principais causas de morte infantil em nosso país. Atualmente tem sido visto como uma doença crônica e com perspectiva de cura em um grande número de casos, pois $2 / 3$ dos cânceres infantis podem ser considerados curáveis se o diagnóstico for precoce e preciso e se a terapêutica instituída for adequada ${ }^{(7)}$.

No entanto, com o aumento da perspectiva de cura para um grande número de crianças o objetivo da assistência sofreu alteração e numa perspectiva mais atual passa a ser o de tentar proporcionar uma melhor qualidade de vida e diminuir as seqüelas levando em consideração a integridade da criança, atendendo os aspectos para além da teoria. A assistência à criança deve ser realizada com base no câncer infantil como uma doença crônica que reflete toda a sua problemática na vida adulta em desenvolvimento ${ }^{(6,8)}$.

É nesse contexto que a enfermagem precisa se inserir, de modo a assistir a criança e sua família convivendo com uma doença crônica, que requer anos de tratamento com muitos efeitos iatrogênicos, determinando transformações nas relações sociais e pessoais ${ }^{(6)}$.

Uma compreensão mais afinada dos aspectos psicológicos, emocionais e sociais que envolvem a criança com câncer e sua família, respeitando suas individualidades e especificidades, enfim, toda a complexidade desse ser em crescimento inserido em um meio sócio-cultural-religioso contribui para uma assistência de enfermagem integral a esta clientela.

Nesse sentido, este trabalho teve por objetivo identificar o significado que a criança atribui ao adoecimento e causas da doença.

\section{METODOLOGIA}

Este trabalho insere-se na tradição hermenêutica de pesquisa norteada por pressupostos epistemológicos construtivistas e utiliza como método de análise as representações sociais que são modalidades de conhecimento prático orientado para a compreensão do mundo e para a comuni-cação sendo, enquanto formas de conhe-cimento que orientam as ações do 
cotidiano, desencadeadas em decorrência das forças dos conteúdos que circulam em nossa sociedade e das forças decorrentes do próprio processo de interação social e das pressões para definir uma dada situação de forma a confirmar e manter identidades coletivas. Sendo assim, esse método não leva em consideração o indivíduo isolado, mas sim as respostas individuais enquanto manifestação das tendências do grupo a que pertence ou de filiação na qual os indivíduos participam ${ }^{(9)}$.

Para a autora citada ${ }^{(9)}$, as representações sociais são ainda consideradas como uma expressão da realidade intra-individual, uma exteriorização do afeto, estruturas que revelam o poder da criação e de transformação da realidade social. São formas de conhecimento que se manifestam como elementos cognitivos mas, não se reduzem apenas a esses elementos, pois sendo socialmente elaboradas e compartilhadas contribuem para a construção de uma realidade comum possibilitando a comunicação. Assim, as representações sociais devem ser estudadas articulando elementos afetivos, mentais, sociais, integrando a cognição, a linguagem e a comunicação às relações sociais que afetam as representações sociais e à realidade material, social e ideativa sobre a qual elas intervêm.

As representações são sempre de um sujeito sobre um objeto, e nunca reproduções deste objeto; são interpretações da realidade, sendo que a relação com o real nunca é direta, mas sim mediada por categorias históricas e subjetivamente constituída ${ }^{(9)}$.

\section{Amostra \\ Para esse trabalho foram entrevistadas 10 crianças portadoras de câncer, residentes em uma cidade do interior do Município de São Paulo, na faixa etária de 9 a 15 anos, sendo algumas referenciadas pelos "Centros Especializados em Tratamento Oncológico", localizados próximos ao município em que se realizou o estudo e outras foram referenciadas por outras crianças.}

\section{Coleta de dados}

Os dados foram coletados após a aprovação pelo Comitê de Ética em Pesquisa da UFSCar, no período de agosto de 2000 a agosto de 2001, durante as visitas domiciliárias à criança com câncer e sua família, por meio de entrevistas, sendo que estas foram realizadas segundo $o$ consentimento da criança e sua família.

Foram feitas em média duas visitas domiciliárias às famílias de cada uma das crianças, em datas, horários e locais pré agendados pelas mesmas e confirmados quando de suas efetivas realizações. Manteve-se também durante este período, diversos contatos com a criança e sua família, com o intuito de acompanhar a evolução clínica da criança e criar um vínculo de credibilidade e confiança.

A entrevista realizada neste estudo foi do tipo aberta ou livre abordando com a criança a sua doença e tratamento. A entrevista foi gravada e durante o diálogo foram feitos questionamentos esclarecedores, com a finalidade de motivar a criança a complementar as idéias. Isto é, a partir das questões iniciais feitas à ela, conforme se desenrolava seu discurso, seqüencialmente outras questões esclarecedoras eram lançadas, estimulando-a e incentivando-a a prosseguir o diálogo. Havia a preocupação de que as novas questões buscassem estimular e esclarecer a linha de pensamento apresentada pela criança e não fazer surgir ou induzir novos assuntos ou temas em relação à sua experiência com o câncer.

As entrevistas foram realizadas no próprio domicílio da criança visando principalmente não causar à criança mais um desgaste emocional, considerando que, junto aos seus familiares e no seu ambiente ela estaria tranqüila para falar sobre suas lembranças, na maioria das vezes dolorosas, frente a experiência com a doença. A criança teve a liberdade de falar o que quisesse e interromper a qualquer momento, no entanto, elas se colocaram na maioria das vezes, com muita tranqüilidade e sem marcas de cansaço, apenas demonstrando muita emoção em alguns momentos.

\section{ANÁLISE DOS DADOS}

Com as entrevistas realizadas foi possível identificar as seguintes categorias: a representação sobre a doença (câncer), a representação sobre a instituição e aos profissionais de saúde e a representação sobre o tratamento. Neste trabalho daremos enfoque à representação sobre a doença e manteremos a fala original das crianças.
Representação socia da criança sobre o câncer 
Elaise Regina G Cagnin Noeli Marchioro L Ferreira Giselle Dupas
Ao falar sobre sua experiência vivenciando a doença, a criança revelou suas idéias e crenças principalmente em relação ao que é o câncer para ela, como se manifestou em sua vida, as explicações do por quê de seu surgimento, as conseqüências trazidas para a sua vida e os sentimentos que surgiram a partir de então. Apresentamos a seguir as categorias elencadas.

\section{Doença ruim que dá medo}

Como era de se esperar, a terminologia câncer está longe de ser empregada pelas crianças portadoras da doença, porém revelam em seus discursos grau considerável de desconhecimento em relação ao câncer. As crianças convivem com determinado problema de saúde mas não projetam significados teóricos e nem algum outro compatível com o entendimento e a experiência vivenciada com o câncer.

Ah, eu precisei fazer tratamento por causa do meu olho, porque ele teve é (...) como é que fala? ... ah, esqueci! Ah, um problema no olho! Eu tive um tumor no olho ! (...) Ah, não sei! (Criança 5)

Para outras crianças, os sentimentos que afloram frente à doença e ao tratamento podem englobar as percepções mais inquietantes e ela faz a representação da doença considerando sua seriedade e gravidade, a busca do por quê das causas e dependendo do estágio em que se encontra, a convivência com a perspectiva da morte.

(...) eu achava que era uma doença grave, eu tinha medo! (...) eu tinha medo de acontecer alguma coisa! (Criança 4)

Em muitas situações, o conhecimento que a criança tem em relação à doença, não foi formulado ou adquirido previamente ao desvelamento de seu diagnóstico, como podemos compreender em suas falas. A criança demonstra que, ela e sua família possuem uma bagagem de conhecimento muito diminuta sobre o assunto, utilizandose de outros artifícios para retratar a doença.

Eu sempre ouvia falar de câncer, câncer, mas eu nunca, sei lá, sabia mais ou menos como que ... caía cabelo, estas coisas (...) ficamos com muito medo né, aí ele falou assim ... sua filha tem um câncer maligno (...) minha mãe né, entrou em desespero e eu não sabia o que era, chorava mas não sabia o que era assim, entendeu ... é sei lá, imaginava que era ... nada! (Criança 1)
Pelo que podemos perceber pelos discursos, a criança sabe falar de suas experiências. Os conceitos, as definições não são claras para ela e também "importam" pouco. O que vale é o que ela sente .

Por outro lado, os discursos das crianças submetidas à convivência com a doença, revelam que elas podem atribuir significados à doença, utilizando representações com base nos conceitos teóricos, mais explícitos ao processo fisiológico ou oncogênese.

Ah, é uma disfunção de células, que se reproduz a mais e vai formando uma tipo de, um tumorzinho ... que vai corroendo o osso! ... é tipo de tumor né... na testa tinha, tem né... olha, antes tinha aqui no joelho, na perna, na bacia, no ombro e na cabeça.

(...) é a célula que se reproduz a mais, e forma um tipo de um tumorzinho, que vai corroendo os ossos! (Criança 3)

Dados sobre a distribuição do câncer infantil no Brasil, mostram que a leucemia linfática aguda (LLA) é a mais freqüente ${ }^{(1)}$. Entre as crianças entrevistadas, esta doença mostrou-se presente em $40 \%$ dos casos, de forma que essas crianças, em particular, eram conhecedores do tipo de doença a que foram acometidas.

Porque eu tinha leucemia, tinha que tratar né! (Criança 4)

Ah ... eu não sei ... lau... leucemia ... é uma doença no sangue, muito séria ... eu sei isso! (Criança 8)

Aí arrançaram um pedacinho do caroço, aí falaram que era ... leucemia! (Criança 9)

Ao se manifestar sobre o câncer, a criança mescla os significados que conhece sobre a doença com as fantasias imaginárias usando a sua criatividade infantil. Ela traz a doença para o seu mundo e emite significados condizentes com a sua capacidade de compreensão e com a experiência vivida com o câncer.

É como se fosse um...uma coisa, um objeto, sei lá ... que tenho na cabeça, ele tá crescendo e conforme ele vai crescendo, ele vai me prejudicando, e ele não crescendo ele não me prejudica... eu acho que é isso! (Criança 2)

Ah, ele era... uma bola de um quilo que ficava dentro da minha barriga ! (...) Ah, ele é ... ele era uma bola, grudada com o rim, eu só tenho um rim, eu tirei um rim, do lado esquerdo... eu operei o intestino! Era uma bola... de sangue, grande... (Criança 7) 
Atualmente, o câncer transformou-se de uma doença infalivelmente fatal para uma doença crônica, de evolução progressiva e passível de cura, mas com índice de mortalidade infantil relativamente alto, por diversos motivos. Na visão da criança, a possibilidade da morte faz parte da conscientização em relação à doença, a criança sabe de sua significativa presença e enigma, e ainda, que todo o sofrimento com o tratamento serve para reunir esforços necessários para garantir o fôlego de vida.

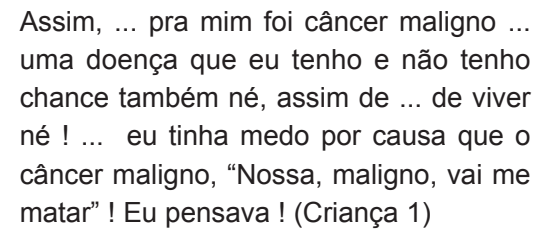

Apesar das crianças saberem sobre a sua doença, algumas vezes não conseguem avaliar a gravidade do seu caso em particular, por isso acreditam encontrar-se acometidas por um tipo menos invasivo e não recidivante, adotando comportamentos de defesa contra as ameaças.

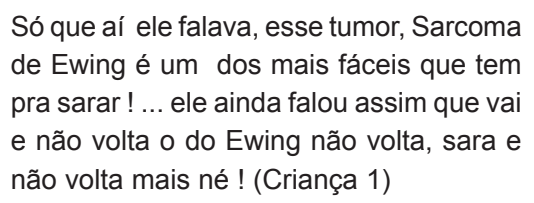

Ainda se consideram únicos, não encontrando nos outros pacientes alguém que partilhasse da similaridade com o tipo de câncer que apresenta.

Das vezes que eu vou lá, eu nunca vi quem tem problema igual o meu, agora eu não sei ... não sei ! (Criança 2)

O modo como a criança vai compreender o câncer está ainda vinculado ao meio social a que ela está inserida, mais explicitamente a opiniões, tendências e influências da sociedade. A criança manifesta que a mídia, o conceito de outras pessoas a respeito da doença influenciaram-na perante o seu diagnóstico, como pode-se observar.

Nossa, câncer maligno ! eu escutava assim na televisão falar, parecia uma coisa assim tão (sinal negativo com a cabeça) nossa... coitadinho daquele, falava né! (...) Porque todo mundo fala que, ai, ai ... ai judiação! ... porque morre, porque não sei o que ... só se for benigno, mas o maligno ... (Criança 1)
Por outro lado, percebemos que a criança mesmo frente aos conflitos de idéias, imaginações, sentimentos e significados e em meio às percepções e vivências em situações delicadas, algumas vezes constrói uma imagem própria à respeito da doença, contrariando os conceitos anteriores, como podemos observar na fala.

\section{E vi que não é assim o câncer maligno, ... se você tiver força você vai e consegue! (Criança 1)}

Alguns autores criticam a abordagem cognitiva e desenvolvimental com relação aos conceitos de doença emitidos por crianças e propõe um paradigma alternativo, afirmando que experiências específicas (como ter uma doença) têm um papel na formação de conceitos, sendo que crianças e adultos podem organizar informações e desempenho bastante similares, quando o grau de experiência é equivalente ${ }^{(10)}$.

\section{Doença que cresce em caroços e causa dor}

O câncer infantil corresponde a um grupo de várias doenças que têm em comum a proliferação descontrolada de células anormais e que pode acometer qualquer local do organismo. Analisando o discurso da criança, compreendemos que ela descreve as manifestações de sua doença enfatizando os sinais e sintomas que precederam o diagnóstico e como se deu o desdobramento das preocupações que suscitaram-na.

Para ela, o câncer pode manifestar-se inicialmente por sinais e sintomas comuns à diversas outras moléstias, o que o faz parecer sem importância, não sendo preciso alterar sua rotina, interromper qualquer hábito, prática de esportes, enfim, nem fazendo-se necessário qualquer medida súbita, surgindo também resistência à procura pela consulta médica.

Eu bati a perna numa caixa... ficou vermeIho só, o lugar ! Vermelho como quando se dá uma pancada na parede ou uma coisinha assim sabe ! ... depois de duas semanas assim, parecia assim um carocinho sabe, de feijão assim ... pareceu uma pele em volta daquilo(...)Aí eu não liguei assim ... eu continuei fazendo ginástica olímpica e caratê (...) Aí eu não queria ir também no médico, nem aqui no Dr. T. eu não queria ir né ... mas aí a minha mãe marcou a consulta. (Criança 1)
Representação social da criança sobre o câncer 
Elaise Regina G Cagnin Noeli Marchioro L Ferreira Giselle Dupas
Só que daí eu comecei com muita dor nas costas, e o Dr. S. falou que não era nada, uma vértebra quebrada, que iria endireitar! ... Fiquei em casa, aí começou a doer de novo, aí já eram duas. Aí...ele engessou; aí engessou passou as dores... (Criança 3$)$

Outras vezes afirmam que a doença manifesta-se por sinais e sintomas estranhos e preocupantes tanto pela evolução, com caráter inconciliável e aparência distinta de outras enfermidades amenas, ou semelhante aos conhecidos como característico de doenças neoplásicas.

Depois de duas semanas assim, parecia assim um carocinho sabe, de feijão assim ... pareceu uma pele em volta daquilo ... era engraçado, quando mexia parecia um ossinho assim, era engraçado né ! (...) aí foi forçando, e começou inchar e saiu uma bola pra fora assim e em cima da pele um caroço alto. (Criança 1)

Começou nascer uns caroços aqui aí eu fiz uma cirurgia aqui né ... aí rancaram ... um pedacinho do caroço ... (Criança 9)

A criança também demonstra que, a presença de sintomatologia advinda da doença, ou seja, a sensação de que "há algo de errado em seu corpo", faz iniciar a busca pela elucidação destas manifestações clínicas. $\mathrm{O}$ esclarecimento do diagnóstico médico freqüentemente envolve uma longa caminhada, principiando, muitas vezes, pelas sugestões de pessoas próximas ${ }^{(10)}$.

\section{Minha mãe foi mostra pra vizinha que, ela ficava apertando assim, e falava, olha, é estranho tem uma bola aqui ! Aí a vizinha falava, ah, deve ser alguma coisa ! (Criança 7)}

Informa que a busca se inicia passando por diferentes especialidades médicas, e por vezes terminando em achados diagnósticos errados, o que acaba atrasando a assimilação de uma doença neoplásica, e conseqüentemente o início do tratamento, e o favorecimento de complicações.

Uma época que eu não andava...fiquei um mês e meio sem andar, só na cama! (...) minha perna dormiu! ... o médico falou assim que foi uma estafa na medula, podia relar assim que eu não sentia ela! Mais ou menos um mês e meio...fiquei deitada. Aí depois começou sabe, igual bebezinho, ia gatinhando...aí depois eu comecei a ficar em pé de novo, quando eu fui para " $R$ " eu tava meia mole ainda, não conseguia andar direito ! (...) Começou doer o corpo em vários lugares; aqui no ombro ficou um calombo ... e foi sumindo, nossa, ficou enorme, só que depois aí sumiu ! Eu tirei chapa e não dava nada, aí deixaram ! (Criança 3)

Aí minha mãe levou eu num doutor aqui de S.C., ele falava, ah, não é nada ! Aí eu fui tomando vitamina e ele foi crescendo ! (Criança 7)

$\mathrm{Na}$ maioria das situações, as constantes buscas pelo diagnóstico culminam em encaminhamentos para centros especializados no tratamento de câncer infantil e concomitantemente, na realização de vários exames e procedimento cirúrgico para se firmar o diagnóstico.

Enquanto que a criança e sua família, nesta situação, buscam incansavelmente e até desesperadamente, a confirmação do diagnóstico - mais precisamente, almejando até as últimas instâncias que não se confirme a presença da doença. Para tanto, consideram necessário a realização de outras consultas médica, concordam com os encaminhamentos, julgam ser melhor consultar outro profissional, enfim, demonstram a não aceitação da doença.

E o Dr. S. falou que não era nada (...) e, aí depois eu fui em outro médico (...) e agora eu estou tratando com uma neuro. (Criança 3)

A confirmação da doença neoplásica é acompanhada por um tumulto de sentimentos, constituindo uma situação apreensiva não só para a família, como também para os profissionais de saúde. O câncer representa um impacto desestruturador, que ameaça o equilíbrio pessoal e o bem estar familiar $^{(11)}$.

\section{Doença que vem castigar e ensinar}

As causas do câncer são variadas, podendo ser externas ou internas ao organismo, estando ambas inter-relacionadas. As causas externas relacionam-se ao meio ambiente e aos hábitos ou costumes próprios do ambiente social e cultural. As causas internas são, na maioria das vezes, geneticamente pré-determinadas, estando ligadas à capacidade do organismo de se defender das agressões externas. De todos 
os casos, 80 a 90\% dos cânceres são associados a fatores ambientais, sendo alguns deles bem conhecidos, como o cigarro, a exposição excessiva ao sol e alguns vírus. Outros, estão em estudo, tais como alguns componentes de alimentos, e muitos outros ainda completamente desconhecidos ${ }^{(3)}$.

O discurso da criança retrata que a vivência com a doença neoplásica faz suscitar várias indagações no que diz respeito ao "por quê de seu surgimento", ou seja, a causa atribuída pela criança ao seu adoecimento. Ao serem abordadas algumas crianças se manifestam com dúvidas e inquietações.

\section{Ainda não cheguei a nenhuma resposta!} (Criança 5)

Ah, a causa de eu tá doente ... não sei ... eu nunca cheguei numa conclusão! (Criança 7)

Da mesma forma, as questões relacionadas a esse assunto são inquietantes para a criança pois na qualidade de "criança doente" indaga-se sobre seu próprio acometimento e como podemos observar nas falas o tema da morte, o medo, a incerteza, a tristeza, a angústia, são vivenciados por todos os envolvidos, direta ou indiretamente com o câncer, fazendo-se presente de forma silenciosa ou alarmante.

Eu ficava no meu quarto assim sozinha ... eu e a minha mãe ... eu falava assim para a minha mãe, Mãe, por que eu estou assim? Será que eu vou morrer mãe? (Criança 7)

Eu fico chorando por isso, eu fico resmungando ...Ah, por que foi acontecer isso comigo? Por que eu estou assim? (Criança 8)

A representação criada sobre a causa do seu adoecimento é influenciada pelo convívio sócio-econômico-cultural e inclusive religioso, ou melhor, pelas opiniões das pessoas envolvidas no leque de inter-relações da criança. Assim, o surgimento da doença é atribuído às pessoas segundo o mandato de uma força superior, as divindades. $\mathrm{O}$ adoecer se dá sob a forma de castigo por algo ou algum comportamento que desagrada as forças divinas ou que contraria aquele aceito socialmente - conceito este passado culturalmente entre as gerações;
Ah, eu acho que vai depender da pessoa, se a pessoa é ruim ou se não é ! No meu caso não, ah ... eu acho que eu não sou ruim! Não, mas pode ser também as pessoas chatas, ruim, pão dura! Porque assim, Deus ... tem gente que fala que Deus que faz isto, que é pra deixar as pessoas de castigo! (Criança 5)

ou por conta do destino, encarregado de preparar as pessoas para alguma adversidade futura ou ensinar o ser humano por meio do sofrimento do próximo.

Ah, eu acho que tinha que acontecer isso!
Porque cada pessoa tem que passar por
uma fase né ? (Criança 8 )

Eu estou aprendendo alguma coisa com isso, ou ensinando bastante gente, entendeu? Ou a gente está aprendendo alguma coisa para levar para a gente, vai que precisa mais pra frente em alguma coisa! (Criança 1)

Sendo essa a visão expressada pela criança doente e projetada para o seu "eu" dando significados próprios ao acometimento, aceitando ou não estes atributos.

Ah, porque tem gente que fala assim que é Deus que faz isso, mas não é né ? (Criança 9)

Porque assim, Deus ... tem gente que fala que Deus que faz isto, que é pra deixar as pessoas de castigo ! Não, eu acho que não foi isso ... acho que é mentira das pessoas ! (...) Ah, eu acho que vai depende da pessoa, se a pessoa é ruim ou se não é! (Criança 5)

A criança doente pode passar a atribuir causas externas a sua enfermidade, não apenas relacionadas ao meio ambiente e aos hábitos ou costumes próprios do ambiente sócio-cultural. As vezes ela acredita na transmissão da doença do animal para o homem o que não é cientificamente comprovado.

Não sei também ... acho que eu peguei do cachorrinho meu! Eu tinha um cachorrinho, só que assim...fila!...não sei, ninguém me falou ... eu acho ! (Criança 9)

$\mathrm{O}$ enfoque psicossocial da criança com câncer engloba compreendê-la quanto às suas crenças e aos sentimentos em relação à doença, o que influencia não apenas na sua adaptação ao tratamento e aos efeitos que o mesmo causa, mas também sobre o curso da própria doença ${ }^{(11)}$.
Representação socia da criança sobre o câncer 
Elaise Regina G Cagnin Noeli Marchioro L Ferreira Giselle Dupas

\section{Doença que limita e deforma}

A criança enfatiza em seu discurso que, a partir do momento em que se define o diagnóstico de câncer, uma gama de sentimentos passa a envolvê-la trazendo conseqüências e repercussão para a vida da criança e de sua família. Relatam uma grande negatividade no fato de que agora estar doente e ter de suportar um tratamento difícil, uma vez que gostariam de ser saudáveis.

Não trouxe nada de bom ! Nada de bom, por que acha que eu queria ficar doente? ... eu não ! (Criança 9)

Eu queria ser saudável! Sei lá, se você está fazendo químio é porque está doente ! (Criança 3)

A criança ressalta que com a doença ela passa sentir indisposições orgânicas, como os sintomas comuns de menor complexidade - os mal-estar, a perda de peso, as hemorragias, as dores, enfim,

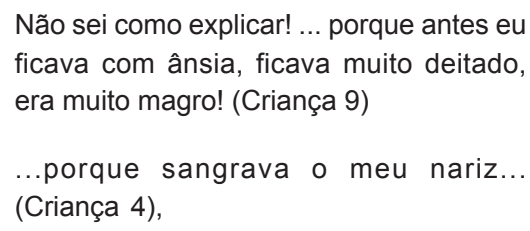

ou sintomas e sinais orgânicos mais complexos, que levam direta e indiretamente, à limitações físicas e psicológicas - como impossibilidade de deambulação, ausência de sensibilidade tátil, a queda de cabelo, a cifose, entre outros.

Uma época que eu não andava ... fiquei um mês e meio sem andar, só na cama !.. minha perna dormiu ! ... o médico falou assim que foi uma estafa na medula, podia relar assim que eu não sentia ela ! (Criança 3)

Porque eu tenho cifose nas costas ... e o meu pescoço tava ficando assim ó, passa a mão, ... alí ainda dá pra ver. (...) É ! ...esse calombinho aí é aonde o tumor já pegou ... é a T1 e T2 ! ... O médico falou que se eu continuar assim vou ter de usar de novo o colete ! (...) É que as minhas costas ... por causa da postura ... Eu tirava e ficava assim também ... né, ficava pendurada, o pescoço vinha pra frente assim, pro lado! (Criança 3)

De modo geral, essas complicações orgânicas podem tornar-se irreversíveis, e até gradativamente mais sérias. Segundo a criança, surgem complicações de caráter acumulativos que se agravam com o crescimento e desenvolvimento do organismo e com a evolução do câncer, evidenciando em algumas situações cegueira, amputações, entre outras até a morte.

Que nem, conforme ele vai crescendo ele vai afetando a vista né ... (...) eu vou perdendo a vista, (pausa) desse olho aqui eu já não enxergo muito bem, desse aqui eu já enxergo melhor ! (...) então já me prejudicou ! (Criança 2)

É pior porque assim, a pessoa (...) se for no coração, a pessoa não pode mais ... ela pode morrer, na perna a pessoa não pode mais andar, e no olho a pessoa não pode mais enxergar com o olho! (Criança 5)

Ao falar sobre as conseqüências de estar doente, relata que o diagnóstico do câncer faz com que se inicie uma série de cuidados e procedimentos envolvidos diretamente com o tratamento.

É ... tirar sangue, tirar liquido da espinha ...
(Criança 8)

... tem que ficar quase todo dia se furando, furando aqui, furando aqui ... ah, também tem que faze quimioterapia (Criança 9)

... fazia um monte de injeção, isso daí! (Criança 7)

As punções para coleta de líquor e sangue, a administração de injeções, as sessões de quimioterapia, o uso de equipamentos de proteção, entre outros, são procedimentos que passam a fazer parte da rotina da criança em tratamento oncológico.

Analisando seu discurso, comprovamos que a doença neoplásica pode, também, acarretar outras conseqüências envolvendo os aspectos emocionais e afetivos da criança.

Mas aí né, eu tinha medo porque sangrava o meu nariz, aí eu entendi umas coisas diferentes ! Eu pensava umas coisas diferentes! (Criança 4)

A criança vê suas relações afetivas alteradas por conta do seu diagnóstico, solidificando a aproximação com outras pessoas ou afastando a criança do convívio social.

Porque todo mundo assim, que eu tinha amizade assim, ficava em cima de mim, sofria também junto né ? (Criança 1) 
Depois que eu comecei ... ah, ninguém

queria brincar comigo! (Criança 7)

Medo, angústias, entendimentos e pensamentos diferentes, inquietações, limitações, perda de função orgânica, aproximação solidária, isolamento social, convivência constante com a perspectiva de morte, enfim, são alterações nas relações afetivas, emocionais e sociais que retratam as repercussões da doença na vida da criança e sua família.

\section{Doença que deixa triste e faz pensar}

Para a criança, o acometimento pelo câncer é permeado por sentimentos diversos gerados frente a toda problemática que envolve o "estar doente" e o "fazer tratamento". Em seu discurso, constata-se a incerteza experimentada frente a tudo o que está acontecendo, a incompreensão da doença, do tratamento e das alterações que de modo dinâmico ocorrem.

Assim, o diagnóstico de câncer infantil, suscita um entrelaçado de questões e suposições, que englobam desde o "por quê eu estou doente ?" até o "será que eu posso morrer?"

Não sei, eu fico pensando assim, Nossa, porque tanta gente né ... a gente pensa assim que nunca é com a gente né, sempre é com os outros... Ai, coitadinho do fulano lá né ... eu, nossa ! Depois que, na hora que eu descobri, nossa eu estou doente agora !! (...) depois aconteceu comigo assim eu fiquei com medo porque Nossa, comigo !?, por que comigo né!? (...) tanta gente foi acontecer comigo, pensava, e não é assim né ? E eu tinha medo né, mas daí ao mesmo tempo eu fui compreendendo assim, fui aprendendo bastante coisa ! (Criança 1)

Eu falo assim, Ai, por que foi acontecer isso daqui comigo, po rque ... por que foi acontecer isso daqui comigo, só comigo acontece essas coisas hein, por que hein ? (Criança 5)

Eu pensava assim, Por que eu fui fica doente? Por que que acontece isso comigo? ...não devia ter acontecido comigo, devia te acontecido com as minha amiga, com a G., não podia acontece comigo ! (...) Eu tinha medo de morrer ! (...) Ah, pensava ... eu pensava assim, Ah, não sei porque eu fui ser doente né ! (Criança 7)
Entretanto, frente a tantas indagações, algumas crianças consideram ser necessário adotar um comportamento protetor, que a coloque a margem de tudo o que diz respeito a sua doença e às implicações que ela pode trazer na sua vida!

Por isso eu não pergunto pra minha mãe

... nada ! Eu não gosto de saber ... porque depois eu fico pensando de noite !... pensando "Será que eu vou morrer ?" (...) eu falava: "Mãe, eu não quero que você fala nada dessa doença pra mim, porque eu não gosto de sabe disso!" (Criança 9)

Preferem abolir os diálogos que fazem alusão à doença, tentando extrair essa realidade dos seus pensamentos e assim, diminuir o sofrimento provocados pela aquisição de conhecimento sobre a doença, e até mesmo, pela citação da palavra "câncer".

Em seu discurso, a criança relata que o fato de estar doente faz emergir diversos sentimentos, acentuados com as terapêuticas oncológicas, com o próprio "sentir-se doente", entre outras coisas, com a percepção de estar sofrendo, de sentir-se triste, da necessidade de chorar, da ansiedade frente a doença e da possibilidade de morte e de maneira oposta, da esperança de um dia conseguir a cura.

Eu fiquei doente ... sofri muito ! É ... e foi muito triste! (...) Ah, porque aconteceu um monte de coisa que deixava eu triste! ... dava muita tristeza ter que passar por tudo aquilo ... ter que sofrer tanto! (Criança 8)

Tem vez que eu fico chorando, quando eu fico triste ! (Criança 5)

Eu pensava umas coisas diferentes! Pensava que ( os olhos encheram-se de lágrima ) pensava que era uma doença grave que eu podia morrer! Aí eu ficava nervosa ! Eu pensava só em chorar! ... chorava muito! (Criança 4)

Por fim, a criança assume que o término das intervenções terapêuticas não corresponde a cessação do sofrimento,

Eu procuro esquecer pra não ficar lembrando ! ... é chato ficar lembrando ... eu penso que vai começar tudo de novo ... eu tenho medo ! (Criança 9)

Nesta fase, há a continuidade desse entrelaçado de sentimentos e a permanente
Representação socia da criança sobre o câncer 
Elaise Regina G Cagnin Noeli Marchioro L Ferreira Giselle Dupas convivência com o sofrimento psicológico, ambos aguçados agora com a incerteza de recidiva, insegurança e o medo de que "tudo comece novamente !" O prazer da finalização do tratamento ${ }^{(12)}$ é dificilmente sentido pelas famílias que não conseguem se desvincular da experiência vivenciada com a doença.

\section{CONSIDERAÇÕES FINAIS}

Analisando os discursos, constatamos que ao ser confirmado o diagnóstico de câncer infantil, surge na vida da criança e sua família, um entrelaçado de questões e suposições, quanto a essa nova experiência que estão vivenciando. Entretanto, frente a tantas indagações, algumas crianças adotam um comportamento protetor, por exemplo, preferindo abolir os diálogos que fazem alusão à "doença". O fato de estarem doentes faz emergir uma gama complexa de sentimentos, acentuados com as terapêuticas oncológicas e com o próprio "sentir-se doente". A experiência com esta situação, permite que elaborem suas próprias compreensões à respeito de seus sentimentos, ao longo da evolução da doença, de maneira que, mesmo

\section{REFERÊNCIAS}

(1) Instituto Nacional do Câncer. O que é câncer. Disponível em: <http://www.inca.org.br/ cancer.html $>$ (25 jul. 2001)

(2) Smeltzer SC, Bare BC. Brunner/Suddarth: tratado de enfermagem médico-cirúrgica. $9^{\mathrm{a}} \mathrm{ed}$. Rio de Janeiro: Guanabara Koogan; 2002.

(3) Instituto Nacional do Câncer. Epidemiologia dos tumores da criança e do adolescentes. Disponível em: <http://www.inca.org.br/ epidemiologia/criança_e_adolescente.html > (25 jul. 2001)

(4) Kowalski LP, Anelli A, Salvajoli JJ, Lopes LF. Manual de condutas diagnósticas e terapêuticas em oncologia. $2^{\mathrm{a}}$ ed. São Paulo: Âmbito; 2002.

(5) Ministério da Saúde. Secretaria Nacional de Assistência à Saúde. Instituto Nacional de Câncer. Ações de Enfermagem para o controle do câncer: uma proposta de integração ensino-serviço. Rio de Janeiro: INCA; 2002.

(6) Lima RAG. A enfermagem na assistência à criança com câncer. Goiânia : AB; 1995.

(7) Lima RAG. Experiências de pais e de outros familiares de crianças e adolescentes com câncer: bases para os cuidados paliativos. [livredocência]. Ribeirão Preto (SP): Escola de Enfermagem de Ribeirão Preto da USP; 2002. conseguindo a "cura", seus sentimentos estarão aguçados agora com a incerteza de recidiva, insegurança e o medo de que "tudo comece novamente!"

$\mathrm{Na}$ visão da criança, a possibilidade da morte faz parte da conscientização em relação à doença, ela sabe de sua significativa presença e enigma, e ainda, que todo o sofrimento com o tratamento serve para reunir esforços necessários para garantir o fôlego de vida, no entanto algumas vezes não conseguem avaliar a gravidade do seu caso em particular. O modo como a criança vai compreender o câncer está também vinculado ao meio social a que está inserida, à opiniões e influências da sociedade, mas mesmo sujeita a todas essas circunstâncias, ela constrói uma imagem própria à respeito da doença, vinculada a evolução de sua própria experiência.

Neste sentido, para essas crianças o câncer causa medo, cresce em caroços que causam dor, vem castigar e ensinar, limita e deforma, deixa triste e faz pensar. Acreditamos que a compreensão destas falas auxiliam o planejamento de assistência a essa clientela.

(8) Valle ERM. Câncer infantil: compreender e agir. Campinas : Psy II; 1997.

(9) Spink MJP. O conceito de representação social na abordagem psicossocial. Cad Saúde Pública 1993; 9 (3): 300-8.

(10) Dupas G. Buscando superar o sofrimento impulsionada pela esperança: a experiência da criança com câncer. [tese]. São Paulo (SP): Escola de Enfermagem da USP; 1997.

(11) Melo LL. Do vivendo para brincar ao brincando para viver: o desvelar da criança com câncer em tratamento ambulatorial na brinquedoteca. [tese]. Ribeirão Preto (SP): Escola de Enfermagem de Ribeirão Preto da USP; 2003.

(12) Oliveira APZ. Buscando a cura: a experiência dos pais da criança que sobrevive ao câncer. [dissertação]. São Paulo (SP): Escola de Enfermagem da USP; 2002. 